\title{
Author Correction: Layer 4 of mouse neocortex differs in cell types and circuit organization between sensory areas
}

\author{
Federico Scala1,2,9, Dmitry Kobak (iD ${ }^{3,9}$, Shen Shan (10) 1,2, Yves Bernaerts ${ }^{3}$, Sophie Laturnus ${ }^{3}$, \\ Cathryn Rene Cadwell (10) 4, Leonard Hartmanis ${ }^{5}$, Emmanouil Froudarakis (10) 1,2, Jesus Ramon Castro ${ }^{1,2}$, \\ Zheng Huan Tan ${ }^{1,2}$, Stelios Papadopoulos ${ }^{1,2}$, Saumil Surendra Patel ${ }^{1,2}$, Rickard Sandberg (1) ${ }^{5}$, Philipp Berens (i) ${ }^{3,6}$, \\ Xiaolong Jiang ${ }^{1,2,7 \star} \&$ Andreas Savas Tolias (1) 1,2,8*
}

Correction to: Nature Communications https://doi.org/10.1038/s41467-019-12058-z, published online 13 September 2019.

The original version of this Article contained an error in the spelling of the author Xiaolong Jiang, which was incorrectly given as Xialong Jiang. This has now been corrected in both the PDF and HTML versions of the Article.

Published online: 04 November 2019

Open Access This article is licensed under a Creative Commons Attribution 4.0 International License, which permits use, sharing, adaptation, distribution and reproduction in any medium or format, as long as you give appropriate credit to the original author(s) and the source, provide a link to the Creative Commons license, and indicate if changes were made. The images or other third party material in this article are included in the article's Creative Commons license, unless indicated otherwise in a credit line to the material. If material is not included in the article's Creative Commons license and your intended use is not permitted by statutory regulation or exceeds the permitted use, you will need to obtain permission directly from the copyright holder. To view a copy of this license, visit http://creativecommons.org/licenses/by/4.0/.
\end{abstract}

This is a U.S. Government work and not under copyright protection in the US; foreign copyright protection may apply 2019

\footnotetext{
${ }^{1}$ Center for Neuroscience and Artificial Intelligence, Baylor College of Medicine, Houston, TX, USA. ${ }^{2}$ Department of Neuroscience, Baylor College of Medicine, Houston, TX, USA. ${ }^{3}$ Institute for Ophthalmic Research, University of Tübingen, Tübingen, Germany. ${ }^{4}$ Department of Anatomic Pathology, University of California San Francisco, San Francisco, CA, USA. ${ }^{5}$ Department of Cell and Molecular Biology, Karolinska Institutet, Stockholm, Sweden. ${ }^{6}$ Department of Computer Science, University of Tübingen, Tübingen, Germany. ${ }^{7}$ Jan and Dan Duncan Neurological Research Institute at Texas Children's Hospital, Houston, TX, USA. ${ }^{8}$ Department of Electrical and Computational Engineering, Rice University, Houston, TX, USA. ${ }^{9}$ These authors contributed equally: Federico Scala, Dmitry Kobak. *email: xiaolonj@bcm.edu; astolias@bcm.edu
} 